Check for updates

Cite this: RSC Adv., 2018, 8, 12975

Received 13th March 2018

DOI: $10.1039 / c 8 r a 02204 f$

rsc.li/rsc-advances Accepted 29th March 2018

\section{Pressure-dependent branching in initial decomposition of gamma-valerolactone: a quantum chemical/RRKM study $\dagger$}

\begin{abstract}
Lili Ye, (D) * Wei Li and Fei Qi
Recently, the potential of gamma-valerolactone (a cyclic ester, $\mathrm{C}_{5} \mathrm{H}_{8} \mathrm{O}_{2}$ ) as a bio-fuel and fuel additive has been highlighted. To unravel its chemical behavior in combustion, the reaction kinetics of initial decomposition of gamma-valerolactone (GVL) has been investigated theoretically by utilizing ab initio calculations and transition-state-theory based simulations. The effect of pressure on decomposition rates and, more importantly, on the branching fractions of major products has been explored. The potential energy surface was constructed at the CCSD(T)-F12/cc-pVDZ-f12 level based on B2PLYPD3/ cc-pVTZ optimized geometries. Rate coefficients were obtained from the solution of RRKM/masterequations at a number of pressures (within the range of 7.6-76 000 torr). The isomerization of GVL to 4-pentenoic acid (4PA) followed by $\mathrm{C}-\mathrm{C}$ bond fission to form allyl plus $\mathrm{CH}_{2} \mathrm{COOH}$ is confirmed to be the most important route in the initial decomposition of GVL. Aside from isomerization to 4PA, several other routes also occur with significant contributions, during which pressure was found to take a great role in their branching. At pressures above 760 torr, the concerted reactions to form $\mathrm{CO}+$ ethene + acetaldehyde and propene +2 -oxiranone account for over $50 \%$ of the overall decomposition at the higher temperature end. On the other hand, the "formally direct formation" of allyl $+\mathrm{CH}_{2} \mathrm{COOH}$, which occurs via directly skipping the 4PA well, has a non-ignorable branching above $1400 \mathrm{~K}$ at low pressures. As opposed to GVL, the effect of pressure on the branching of 4PA consumption routes is very minor. It is hoped that the present study will establish a firm foundation for more comprehensive kinetic studies on GVL combustion in the future.
\end{abstract}

\section{Introduction}

Concerns about the depletion of fossil fuels drive society to search for renewable and sustainable energy sources. Gammavalerolactone $\left(\mathrm{C}_{5} \mathrm{H}_{8} \mathrm{O}_{2}\right.$, Scheme 1$)$, a cyclic ester readily obtainable from cellulosic biomass, exhibits the most important characteristics of an ideal sustainable liquid. Recently, its potential as a promising biofuel and fuel additive has been highlighted and it is attracting increasing attention from researchers. ${ }^{1,2}$ For this novel biomass-derived chemical, the $\Delta_{\mathrm{c}} H_{\mathrm{m}, \mathrm{liq}}{ }^{\theta}$ (standard molar enthalpy of combustion) value is $-2.65 \mathrm{MJ} \mathrm{mol}^{-1}$, between the values of $-1.37 \mathrm{MJ} \mathrm{mol}^{-1}$ for ethanol and $-3.37 \mathrm{MJ} \mathrm{mol}^{-1}$ for methyl tert-butyl ether. Other important fuel properties of gamma-valerolactone (GVL) include a high boiling point, high density, high oxygen content and less formation of dangerous peroxides during combustion. ${ }^{1}$ Studies on the effect of GVL on diesel engine performance, fuel

Key Laboratory for Power Machinery and Engineering of MOE, Shanghai Jiao Tong University, Shanghai 200240, P. R. China.E-mail: yell@sjtu.edu.cn

$\dagger$ Electronic supplementary information (ESI) available: Cartesian coordinates of major species and transition states on $\mathrm{C}_{5} \mathrm{H}_{8} \mathrm{O}_{2}$ potential energy surface. See DOI: 10.1039/c8ra02204f properties and exhaust emissions have recently been carried out. ${ }^{3,4}$ When blending GVL into diesel, an advantageous effect has been generally found on the physicochemical fuel properties and exhaust emissions such as $\mathrm{NO}_{x}$, CO, unburned hydrocarbons and smoke. In contrast to ethanol, GVL does not form an azeotrope with water. The easy removal of water by distillation results in a less energy demanding and cheaper process for its production from biomass.

At present, the interest in GVL is mostly centered on its production routes from cellulose/lignocellulose and on the development of efficient catalysts for reactions thereof. ${ }^{5-10}$ As the key step in its production, the transformation of levulinic

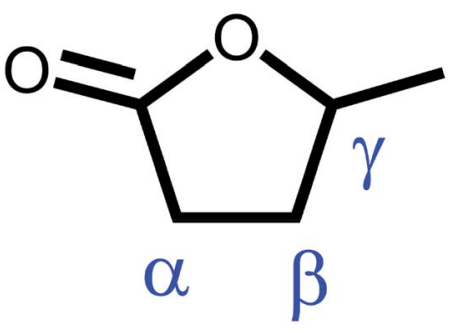

Scheme 1 Schematic structure of gamma-valerolactone (GVL). 
acid to GVL is normally achieved on noble-metal catalyst using $\mathrm{H}_{2}$. Lately, Xue et al. ${ }^{10}$ has synthesized zirconium-cyanuric acid coordination polymer for this conversion process, providing a new route for designing highly efficient catalysts. While the development of efficient catalysts has initiated numerous studies, investigation on its detailed combustion chemistry is just getting started. De Bruycker et al. ${ }^{\mathbf{1 1 , 1 2}}$ studied the thermal decomposition of GVL through the combined techniques of experiment, theory and modeling. The experiments were performed in a tubular flow reactor from $873 \mathrm{~K}$ to $1073 \mathrm{~K}$ at 1275 torr. Thermodynamic and kinetic data were computed at the CBS-QB3 level for key reactions involved. Their study proposes that the isomerization of GVL to 4-pentenoic acid (4PA) followed by $\mathrm{C}-\mathrm{C}$ fission forming allyl and carboxy methyl is an important route for the initial radical pool. Unfortunately, only rate coefficients of two barrier-characterized reactions were computed from theory, and the rate coefficients of direct bond fissions, especially the important $\mathrm{C}_{2}-\mathrm{C}_{3}$ fission in $4 \mathrm{PA}$, were assigned from estimation. Furthermore, the rate coefficients were obtained simply at the high pressure limit for this pressuredependent reaction, with no predictions being made for the falloff region. For the reasons above, an in-depth pressuredependent kinetic study is expected to provide more systematic kinetic data and improve the performance of the De Bruycker model. Following the pyrolysis study, Sudholt et al. ${ }^{13}$ performed an oxidation experiment of GVL in a low pressure premixed flat flame at 50 torr, and a kinetic model of high temperature oxidation was extended from the pyrolysis model of De Bruycker et al. ${ }^{11}$

Kinetic modeling is a powerful tool in using fundamental reaction mechanism to evaluate the engine-relevant behaviors of fuels, such as ignition properties and pollutant emission. To accelerate the application of GVL as a practical fuel, the comprehensive reaction mechanism of GVL combustion needs to be explored in detail, and the core reactions involved must be provided with reliable kinetic data that covers various temperature and pressure conditions. To satisfy this purpose, the present work is dedicated to unravel the initial decomposition mechanism of GVL, and more importantly, to elucidate the effect of pressure on the branching of major decomposition products. This study is expected to lay a firm foundation for more comprehensive kinetic studies on GVL combustion in the future.

\section{Theoretical methodologies}

\subsection{Electronic structure calculations}

The characterization of $\mathrm{C}_{5} \mathrm{H}_{8} \mathrm{O}_{2}$ potential energy surface was performed by using a combination of explicitly correlated CCSD(T)-F12 (ref. 14 and 15) and density functional theory (DFT) methods. The geometric structures and rovibrational properties of reactant, intermediates, transition states and products were obtained by employing the B2PLYPD3 functional and the cc-pVTZ basis set. The B2PLYPD3 method requests the B2PLYP double hybrid functional combined with Grimme's D3BJ dispersion correction. ${ }^{\mathbf{1 6}, 17}$ Methods of this kind combine exact HF exchange with an MP2-like correlation to the DFT calculation, and have similar computational cost as MP2 rather than that of DFT. The connectivity of specific transition state to its adjacent local minima were generally examined through visualization of corresponding imaginary vibrational mode. For the ambiguous cases, the intrinsic reaction coordinate (IRC) calculations $^{18}$ were also performed to ensure the correct connectivity of transition state to desired reactant and product. The DFT calculations were done with Gaussian09 program. ${ }^{\mathbf{1 9}}$

High level evaluations of single point energies were computed using the CCSD(T)-F12 method at cc-pVDZ-F12 basis set. $^{20}$ The zero point energies were included from the B2PLYPD3/cc-pVTZ frequency analysis. Note that the $\operatorname{CCSD}(\mathrm{T})-$ F12/cc-pVTZ-f12 level was also tested for several species, and very small difference was found from the energies at cc-pVDZf12 (mostly within $0.5 \mathrm{kcal} \mathrm{mol}^{-1}$ ). Such small difference is presumed to improve the rate coefficients by only a very limited extent. Considering the notably higher expense of $\operatorname{CCSD}(\mathrm{T})-\mathrm{F} 12 /$ cc-pVTZ-f12 calculations, we did not refine the entire potential energy surface using this level. The $\operatorname{CCSD}(\mathrm{T})$-F12 calculations were done with the MOLPRO2015 program. $^{21}$

Direct bond fissions are usually barrierless reactions that have no well-defined saddle points along the reaction coordinate. In this work only the most possible direct bond fissions for each of GVL and 4PA were considered, namely, the $\mathrm{C}-\mathrm{C}$ fission of GVL to lose the side methyl group and the $\mathrm{C}-\mathrm{C}$ fission of 4PA to form allyl plus $\mathrm{CH}_{2} \mathrm{COOH}$, respectively. For these two reactions, the multi-reference methods were employed for accurate description of the interaction potentials between the two reacting moieties. Specifically, the CASPT2(2e,2o)/cc-pVDZ method $^{22}$ was used for the C-C bond fission of GVL to form $\gamma$ radical of gamma-butyrolactone (GBL) and methyl radical. The $(2 \mathrm{e}, 2 \mathrm{o})$ active space simply consists of the two singly occupied radical orbitals. With the $\mathrm{C}-\mathrm{C}$ fission of $4 \mathrm{PA}$ to form allyl plus $\mathrm{CH}_{2} \mathrm{COOH}$, the CASPT2(6e,6o)/cc-pVDZ method was used, where the $(6 e, 60)$ active space consists of $(2 e, 20)$ for $\left(\pi, \pi^{*}\right)$ of $\mathrm{C}=\mathrm{O}$ double bond, $(2 \mathrm{e}, 2 \mathrm{o})$ for $\left(\pi, \pi^{*}\right)$ of $\mathrm{C}=\mathrm{C}$ double bond and $(2 \mathrm{e}, 2 \mathrm{o})$ for the two singly occupied carbon radical orbitals. The three pi electrons on $\mathrm{C}_{3} \mathrm{H}_{5}$ fragment become delocalized when the separation of two reacting fragments gets larger, and (6e,6o) was tested to be the minimal active space for this reaction. High level corrections for the interaction potentials were done with the MRCI method at cc-pVDZ and cc-pVTZ basis sets. ${ }^{23}$ The active spaces in MRCI calculations remained the same with those in CASPT2 calculations, and the Davidson correction was included in final MRCI energies. These multi-reference calculations were done with the MOLPRO2015 program package. ${ }^{21}$

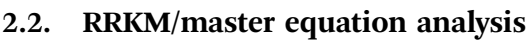

The rate coefficients were calculated via the solution of the timedependent RRKM/master equation using the MESS code. ${ }^{24,25}$ MESS is a newly developed master equation solver by Georgievskii et al., and it aims to effectively and simultaneously calculate temperature- and pressure-dependent rate coefficients for reaction systems with an arbitrary number of wells and bimolecular species. One distinguished feature of this code is the "well-merging" scheme for the treatment of rapidly 
equilibrated species. Specifically, when the rate of chemical interconversion between two species approaches or exceeds the internal energy relaxation rate, these two species will be combined into a new compound and the number of species in master equation simulations will be reduced accordingly by one. Another important feature of this code is the capture of rate coefficients for the so-called "formally direct" channels. The formally direct channels are those that traverse more than one transition state in a single elementary step, without stabilization into in-between wells. This type of channels is formally "direct" but mechanistically "indirect". Rate coefficients of these channels are not the same as the effective rate coefficients that are derived from applying conventional quasi-steady-state assumption to the transient intermediate in a multi-step reaction scheme.

For the present reaction system, the temperature covers a range of $800-2000 \mathrm{~K}$ at a list of pressures (7.6, 76, 760, 7600 and 76000 torr) with $\mathrm{Ar}$ as the bath gas. The interaction between reactant and bath gas was described by the LennardJones model potential. The $(\sigma, \varepsilon)$ parameters were estimated to be $\sigma=5.87 \AA$ and $\varepsilon=304 \mathrm{~cm}^{-1}$ for $\mathrm{C}_{5} \mathrm{H}_{8} \mathrm{O}_{2}$ from the group contribution method of Joback, ${ }^{26}$ and $\sigma=3.47 \AA$ and $\varepsilon=$ $79 \mathrm{~cm}^{-1}$ for Ar from recommendations by Hippler. ${ }^{27}$ The collision induced energy transfer was modeled with the single exponential down model, i.e., $P(\Delta E)=\exp (-\Delta E / \alpha)$, where $P$ is the probability and $\Delta E=E_{\text {initial }}-E_{\text {final }}>0$ The average downwards energy transferred per collision was assumed to follow a temperature-dependent form, i.e., $\left\langle\Delta E_{\text {down }}\right\rangle=200(T / 300)^{0.85}$, which is estimated based on previous experience. ${ }^{28,29}$

For reactions with a pronounced chemical barrier, the conventional transition state theory was applied in RRKM/ master equation analysis, with the transition state dividing surface fixed at the saddle point. Whereas for direct bond fission reactions, the location of optimal transition state normally varies with temperature. During the MESS simulations, the microcanonical variational transition state theory was employed for the minimization of rate constants along the reaction coordinate. Variational procedure for determining microcanonical rate coefficients is as follows. A range of dividing surfaces were selected at different positions along the reaction coordinate, and the sum of states was evaluated appropriate to the given energy and angular momentum at each position. The transition state was identified with the surface that provides the minimum sum of states. The high-pressurelimit rate coefficient is then obtained as the canonical average of the variationally determined microscopic rate coefficients over the Boltzmann population distribution. Eventually, it emerges that the transition state of a barrierless reaction varies with temperature, i.e., moving from larger separation between two fragments at low temperatures to smaller separation at high temperatures.

In addition, the rigid rotor harmonic oscillator (RRHO) approximation was used to deal with the vibrational degrees of freedom. Note that the RRHO frequencies were multiplied by a scale factor of 0.99 as a crude correction for the normal modes obtained from CASPT2 calculations. The internal torsions were treated as one-dimensional hindered rotors, and were removed from the RRHO analysis. The hindrance potentials of the hindered rotors were obtained through relaxed scan along the dihedral coordinate at an interval of 10 degrees, by using the B3LYP/6-311+G(d) level. Furthermore, the quantum tunneling effect, which has a potential to be important for H-transfer reactions at low temperatures, was incorporated using the asymmetric Eckart's potential. ${ }^{30}$

\section{Results and discussion}

\subsection{Reaction mechanism}

Fig. 1 displays the major reaction pathways occurring on the $\mathrm{C}_{5} \mathrm{H}_{8} \mathrm{O}_{2}$ potential energy surface for the initial decomposition of GVL, with the energy of GVL as the zero reference. Schematic structures of the transition states on this surface are shown in Fig. 2. Normal mode frequencies of the major stationary points are provided in Table S1 of the ESI. $\dagger$ Table 1 compares the relative enthalpies at $298 \mathrm{~K}$ calculated in this work with those by De Bruycker et $a l .{ }^{12}$ using the CBS-QB3 method. As can be seen, there is generally a good consistency between the present predictions and the CBS-QB3 values for most of the stationary points or product sets, with exceptions of the three transitions states that characterize the forward conversion of 4PA, i.e., TS6, TS7 and TS8. For the three exceptions, the present evaluations are lower than the CBS-QB3 values by over $1.5 \mathrm{kcal} \mathrm{mol}^{-1}$. These three transition states all have very tight structures and consequently small entropies. Later kinetic analysis results will demonstrate that even an increase of $2 \mathrm{kcal} \mathrm{mol}^{-1}$ for energies of these transition states has little influential effect on the decomposition behavior.

For the initial decomposition of GVL, the lowest bond fission channel is demethylation via direct $\mathrm{C}-\mathrm{C}$ bond cleavage to produce methyl and $\gamma$-radical of butyrolactone. Other direct bond fissions are not shown here because of the high bond dissociation energies. As presented in Fig. 1, the other five channels from GVL are all characterized by pronounced energy barriers. Among them, the most important one is the isomerization to 4-pentenoic acid (4PA) via the lowest barrier, TS1, with the energy of $63.33 \mathrm{kcal} \mathrm{mol}^{-1}$. In this reaction, one hydrogen atom at the methyl group is transferred to the ring oxygen via a four-membered ring transition state, leading to the ringopening process. The present barrier height agrees satisfactorily with the CBS-QB3 value within $1 \mathrm{kcal}^{\mathrm{mol}}{ }^{-1}$. This transition state has an energy of similar magnitude to the 1,3- $\mathrm{H}$ shift reactions in ether systems, such as the decomposition of methyl ethyl ether into methanol plus ethene $\left(65.2 \mathrm{kcal} \mathrm{mol}^{-1}\right)$ and decomposition of ethyl tert-butyl ether into tert-butanol plus ethene $\left(63.4 \mathrm{kcal} \mathrm{mol}^{-1}\right) .^{31}$

The next lowest barrier from GVL is TS3 for the keto-enol tautomerization reaction, where one hydrogen at the carbon atom $\alpha$ to the carbonyl group transfers to the oxygen atom in the carbonyl group. TS3 has a small entropy because of the tight ring structure, implying that this channel could not be important under current conditions. GVL can also proceed by several concerted reactions to lead to separate product species. These concerted reactions are (a) decomposition to propene plus 2oxiranone via TS2 (78.53 $\mathrm{kcal} \mathrm{mol}^{-1}$ ), (b) decarbonylation to 
Table 1 Calculated relative enthalpies $\left(298 \mathrm{~K}, \mathrm{kcal} \mathrm{mol}^{-1}\right)$ in present work [CCSD(T)-F12/cc-pVDZ-F12//B2PLYPD3/cc-pVTZ] and at CBSQB3 Level ${ }^{a}$

\begin{tabular}{|c|c|c|}
\hline & Present work & CBS-QB3 (ref. 12) \\
\hline $\begin{array}{l}\text { Gamma-valerolactone } \\
\text { (GVL) }\end{array}$ & 0.0 & 0.0 \\
\hline$\gamma-\mathrm{GBL}+\mathrm{CH}_{3}$ & 89.81 & 90.78 \\
\hline 4-Pentenoic acid (TS1) & $10.62(63.37)$ & $12.18(64.02)$ \\
\hline $\mathrm{C}_{3} \mathrm{H}_{5}+\mathrm{CH}_{2} \mathrm{COOH}$ & 82.49 & 83.13 \\
\hline $\begin{array}{l}\mathrm{C}_{3} \mathrm{H}_{6}+\mathrm{cy}\left(\mathrm{OCH}_{2} \mathrm{C}\right)=\mathrm{O} \\
(\mathrm{TS} 2)\end{array}$ & $61.88(79.50)$ & $62.11(79.55)$ \\
\hline $\begin{array}{l}\text { 5-Methyl-4,5-dihydro-2-furanol } \\
\text { (TS3) }\end{array}$ & $26.24(75.41)$ & $25.08(76.21)$ \\
\hline $\begin{array}{l}\mathrm{CH}_{2} \mathrm{CO}+\mathrm{CH}_{3} \mathrm{C}(\mathrm{O}) \mathrm{CH}_{3} \\
\text { (TS4) }\end{array}$ & $35.15(107.96)$ & $35.59(107.98)$ \\
\hline $\begin{array}{l}\mathrm{CO}+\mathrm{C}_{2} \mathrm{H}_{4}+\mathrm{CH}_{3} \mathrm{CHO} \\
\text { (TS5) }\end{array}$ & $43.42(81.56)$ & $45.87(81.70)$ \\
\hline $\begin{array}{l}\mathrm{C}_{3} \mathrm{H}_{5} \mathrm{CH}_{2} \mathrm{CO}+\mathrm{H}_{2} \mathrm{O} \\
\text { (TS7) }\end{array}$ & $46.54(86.62)$ & $47.78(88.15)$ \\
\hline $\begin{array}{l}\text { 3-Pentenoic acid } \\
\text { (TS8) }\end{array}$ & $10.51(85.97)$ & $10.27(90.06)$ \\
\hline $\begin{array}{l}\text { 1-Butene }+\mathrm{CO}_{2} \\
\text { (TS6, TS9) }\end{array}$ & $4.17(81.84,50.99)$ & $5.26(83.37,51.36)$ \\
\hline
\end{tabular}

${ }^{a}$ The GVL enthalpy is set as the zero reference. The relative enthalpies of transition states are in parenthesis.

a major role as a result of two factors that take effect in the same direction. First, the barriers of these routes almost all lie above the $\mathrm{C}_{\alpha}-\mathrm{C}_{\beta}$ bond fission energy, and second, they are entropically unfavored compared with direct bond fission process.

Quantum chemical calculations suggest that the most energetically favored route for GVL decomposition is isomerization to 4PA followed by $\mathrm{C}-\mathrm{C}$ fission to form allyl plus $\mathrm{CH}_{2}$ $\mathrm{COOH}$. This route serves as an important source of initial radical pool in the thermal decomposition of GVL.

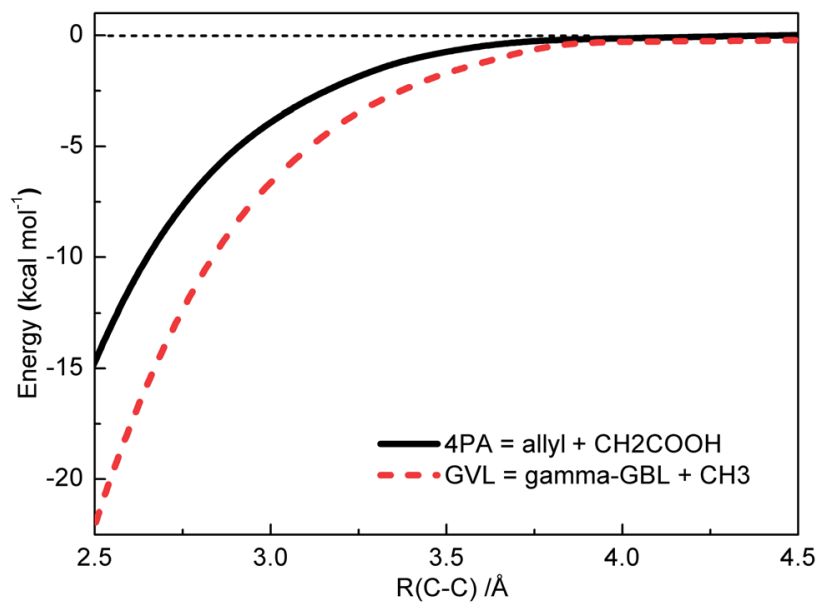

Fig. 3 Minimum energy paths of two barrierless reactions GVL $\rightarrow \gamma$ $\mathrm{GBL}+\mathrm{CH}_{3}$ (dash red line) and 4PA $\rightarrow$ allyl $+\mathrm{CH}_{2} \mathrm{COOH}$ (solid black line). The method used is MRCI/CBS(cc-pVDZ, cc-pVTZ)//CASPT2/ccpVDZ, with $(2 e, 20)$ active space for the former reaction and $(6 e, 60)$ for the latter.

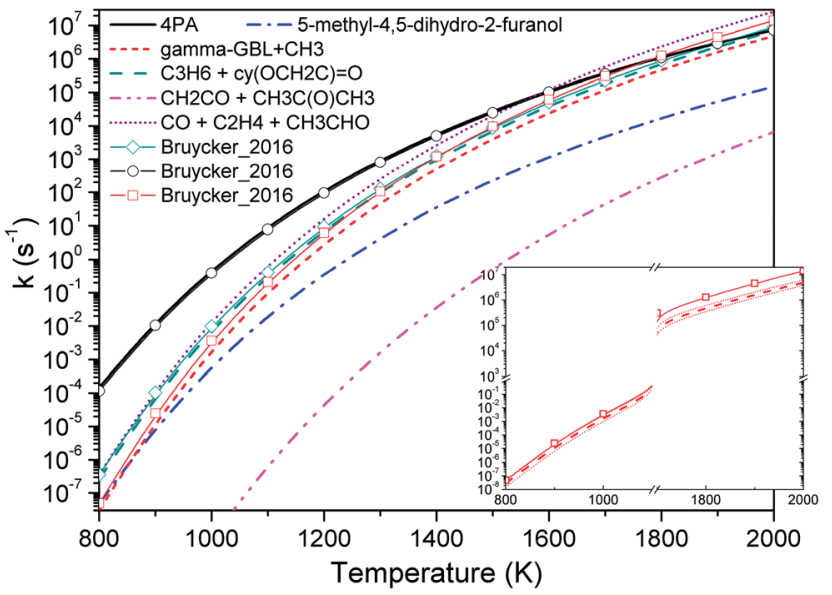

Fig. 4 High pressure limit rate coefficients of major channels for GVL decomposition. Thin lines with symbols are from De Bruycker et al.:12 the green line with diamond and the black line with circle are from transition-state-theory calculations at CBS-QBS level; and the red line with square is from estimations. The inset shows varied rate coefficients within $1 \mathrm{kcal} \mathrm{mol}^{-1}$ of transition state energies for barrierless reaction $\mathrm{GVL} \rightarrow \gamma-\mathrm{GBL}+\mathrm{CH}_{3}$.

\subsection{Reaction kinetics}

3.2.1 High pressure limit rate coefficients. Compared to channels with pronounced chemical barriers, the variational rate coefficients are more dependent on the interaction potentials between the two reacting fragments. In this study, the interaction potentials of the two barrierless channels, i.e., GVL $\rightarrow \gamma$-GBL $+\mathrm{CH}_{3}$ and $4 \mathrm{PA} \rightarrow$ allyl $+\mathrm{CH}_{2} \mathrm{COOH}$, are illustrated in Fig. 3, computed by using the combination of CASPT2 and MRCI methods. Implementation of the variational procedure suggests that the transition states giving the minimum rate coefficients are generally located within the separation of 2.8$3.2 \AA$ between the two fragments for the temperature range of

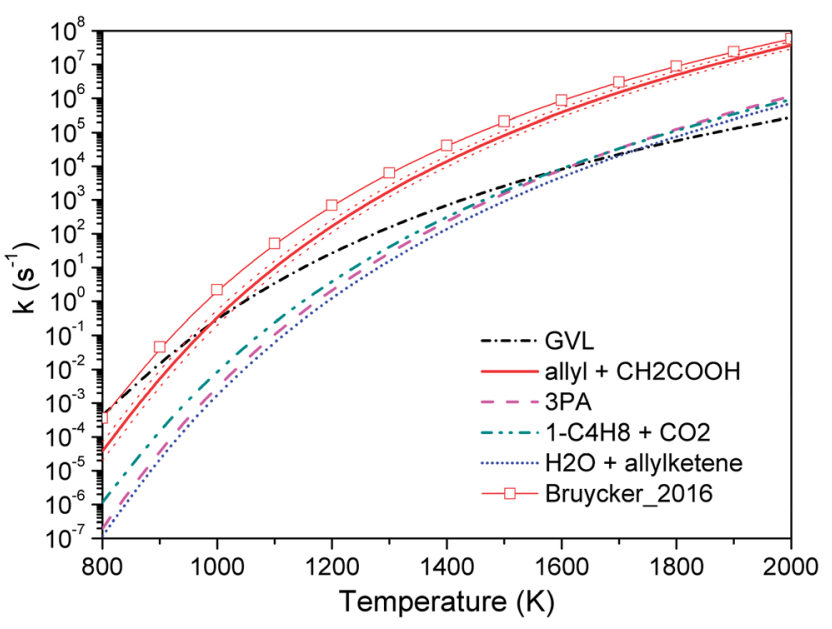

Fig. 5 High pressure limit rate coefficients of 4PA decomposition. The thin line with symbol represents estimations by De Bruycker et al. ${ }^{12}$ The varied rate coefficients of barrierless channel allyl $+\mathrm{CH}_{2} \mathrm{COOH}$ within $1 \mathrm{kcal} \mathrm{mol}{ }^{-1}$ of transition state energies are shown by red dot lines. 


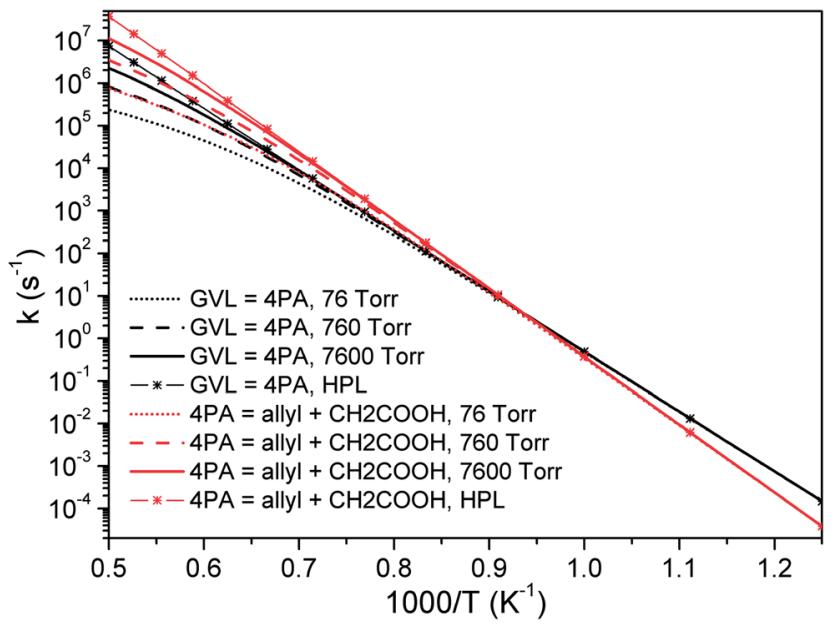

Fig. 6 Pressure-dependent rate coefficients of two most important channels in initial decomposition of GVL: black, GVL $\rightarrow$ 4PA; red, 4PA $\rightarrow$ allyl $+\mathrm{CH}_{2} \mathrm{COOH}$.

800-2000 K. As the temperature increases, the optimal transition state gradually moves to shorter separations.

Fig. 4 compares the high pressure limit rate coefficients of major channels for initial GVL decomposition. It is apparent that the isomerization to $4 \mathrm{PA}$ is the most favored channel except at the high temperature end. Available studies about similar systems are very limited, and only the rate parameters from De Bruycker et al. are illustrated for comparison. ${ }^{11}$ The present work shows an excellent agreement with the results from De Bruycker et al., particularly for the two channels forming $\mathrm{CO}+$ ethene + acetaldehyde and propene +2 -oxiranone (the two sets of results almost superpose each other). For these two channels, the discrepancy of rate coefficients is less than $30 \%$. For the barrierless channel of $\gamma$-GBL $+\mathrm{CH}_{3}$, the present result and estimation by De Bruycker et al. agree well with each other below $1000 \mathrm{~K}$. However, the latter exhibits a faster growth rate as the temperature increases and approximately triples the former at $2000 \mathrm{~K}$. The inset in Fig. 4 illustrates the rate coefficients obtained via varying the transition state energies in a range of $\pm 1 \mathrm{kcal} \mathrm{mol}^{-1}$. It can be seen that De Bruycker's estimations fall within the upper limit of variation below $900 \mathrm{~K}$, but are still a factor of 2 larger than our predictions at the high temperature end. For this channel, the interaction energies and rovibrational frequencies of transition state configurations are assumed to be the largest source of uncertainty. Since relevant studies are very scarce, it is not easy to determine which set of data is more accurate. Fortunately, this channel plays only a minor contribution to the overall kinetics, as will be seen in later discussion. It is possible that kinetic modeling for high temperature pyrolysis of GVL under high pressure conditions could provide useful insight into the importance of this channel.

Regarding the keto-enol tautomerization, although it has the second lowest energy barrier, which is only next to the isomerization barrier, this channel is rather uncompetitive due to the small entropy of the transition state. Moreover, the channel leading to ketene plus acetone is never important under the current conditions.

Fig. 5 shows the high pressure limit rate coefficients of $4 \mathrm{PA}$ consumption occurring over the $\mathrm{C}_{5} \mathrm{H}_{8} \mathrm{O}_{2}$ surface. From this plot, the reaction back to GVL is the dominant channel at lower temperatures because of the enthalpic effect, whereas with temperature increasing the direct bond fission forming allyl plus $\mathrm{CH}_{2} \mathrm{COOH}$ quickly dominates the consumption of $4 \mathrm{PA}$. $\mathrm{H}$ addition to the allyl radical generated from this channel accounts for part of the concentration of propene observed in earlier experimental

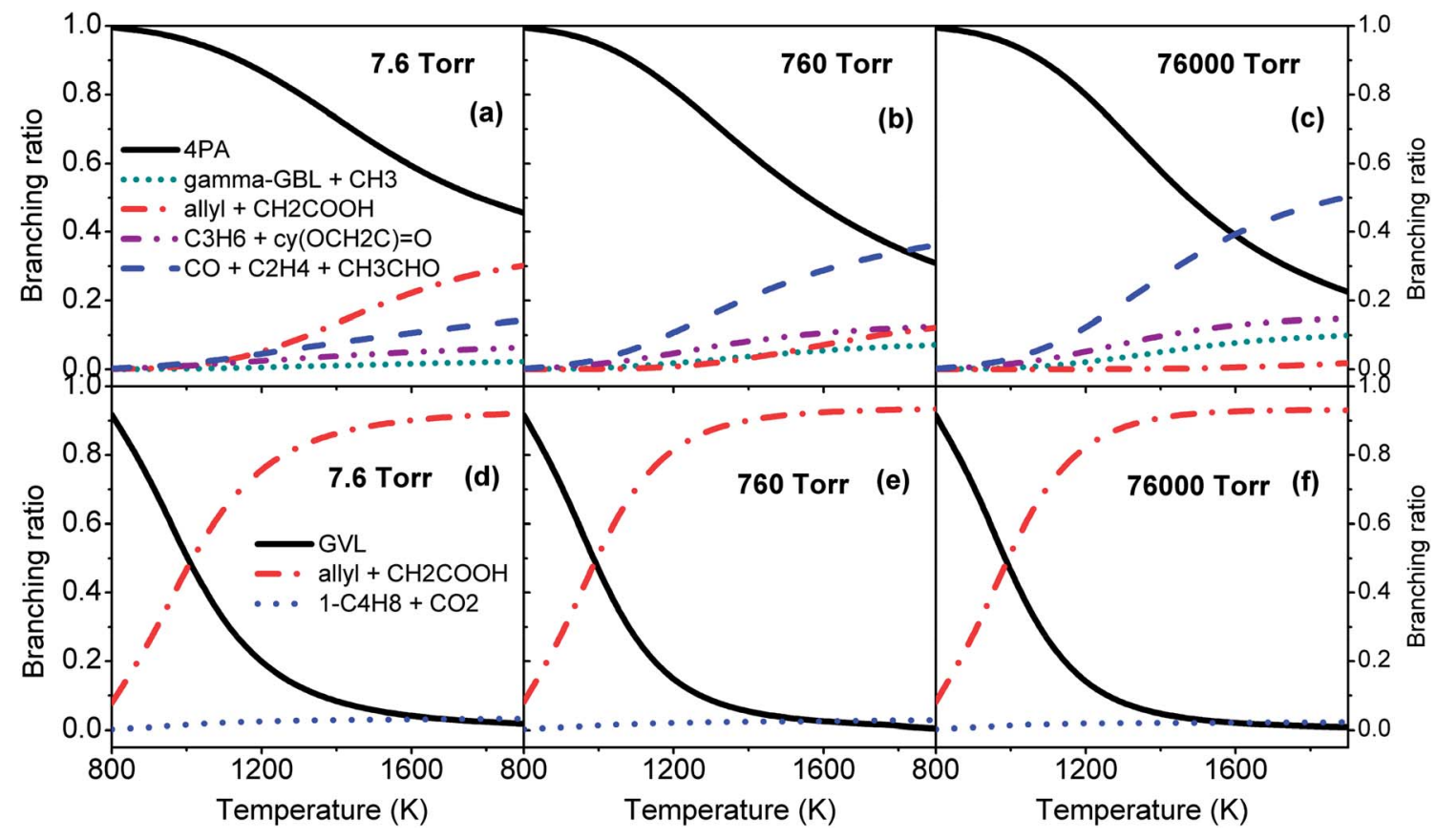

Fig. 7 Branching ratios of major consumption channels for GVL $(a-c)$ and 4PA (d-f) at various pressures. 
studies. ${ }^{11,12}$ The other radical product $\mathrm{CH}_{2} \mathrm{COOH}$ will primarily generate methyl and $\mathrm{CO}_{2}$ via a two-step mechanism: first, intramolecular $\mathrm{H}$-migration to intermediate $\mathrm{CH}_{3} \mathrm{COO}$; second, $\mathrm{C}-\mathrm{C}$ bond fission of $\mathrm{CH}_{3} \mathrm{COO}$ to final products. The $\mathrm{C}-\mathrm{O} \beta$-scission of $\mathrm{CH}_{2} \mathrm{COOH}$ to form $\mathrm{CH}_{2} \mathrm{CO}$ and $\mathrm{OH}$ is expected to be only a minor reaction, and this is in accordance with the fact that no ketenes were detected in related experiments. ${ }^{\mathbf{1 1 , 1 2}}$ The remaining channels of 4PA, such as isomerization to 3PA and dehydration, are insignificant channels.

3.2.2 Effect of pressure on decomposition kinetics and branching. Fig. 6 shows the effect of pressure on the rate coefficients of the two most important channels in initial decomposition of GVL, i.e., GVL $\rightarrow 4 \mathrm{PA}$ and $4 \mathrm{PA} \rightarrow$ allyl $+\mathrm{CH}_{2} \mathrm{COOH}$. It can be seen that pressure has very little effect on the low temperature reactivity of these two channels. Dissociation of 4PA has a much faster growth rate with temperature than the isomerization of GVL to 4PA. At higher temperatures, the C-C fission of 4PA will be much faster than the preceding isomerization step, implying that any formed 4PA will rapidly dissociate into fragmented radicals.

According to De Bruycker et al., ${ }^{12}$ radical chemistry tends to take over from molecular chemistry at high temperatures. This might lead the falloff regime of unimolecular decomposition rate coefficients, which locates just at high temperatures, to be seemingly unimportant. However, it should be noted that the branching fraction of primary decomposition products is quite sensitive to the pressure and the product distribution will certainly affect the subsequent transformation of the formed species.

Fig. 7 plots the branching ratios of major consumption channels for GVL $(\mathrm{a}-\mathrm{c})$ and $4 \mathrm{PA}(\mathrm{d}-\mathrm{f})$ as a function of temperature at the pressures of 7.6, 760 and 76000 Torr. All these panels suggest the great importance of the interconversion between GVL and 4PA, especially at lower temperatures. For GVL, the reactivity of the interconversion channel reduces gradually and the dominance covers a broader temperature range than the situation under high pressure conditions. The considerable amount of allyl $+\mathrm{CH}_{2} \mathrm{COOH}$ in panel (a) can be explained by the formally direct formation mechanism from the initial reactant. At low pressures the collisional stabilization effect is much less significant, so that a part of the excited 4PA* from GVL directly undergoes $\mathrm{C}-\mathrm{C}$ bond fission to form allyl plus $\mathrm{CH}_{2} \mathrm{COOH}$ instead of first being stabilized into the stable 4PA well. As the pressure increases, more of excited 4PA* will be first deactivated via unreactive collisions before being reactivated to dissociate, and this leads to a reduced formation of allyl plus $\mathrm{CH}_{2} \mathrm{COOH}$ directly from GVL. Within the current investigated range, the well-skipping reaction of GVL cannot compete with its conversion to 4PA. Since any formed 4PA will rapidly dissociate into fragmented radicals at higher temperatures, the formation of allyl plus $\mathrm{CH}_{2} \mathrm{COOH}$ will be primarily from the

Table 2 Modified Arrhenius parameters for major channels occurring on the $\mathrm{C}_{5} \mathrm{H}_{8} \mathrm{O}_{2}$ surface ${ }^{a}$

\begin{tabular}{|c|c|c|c|c|c|c|c|c|}
\hline$P$ (torr) & Reactions & $A$ & $n$ & $E$ & Reactions & $A$ & $n$ & $E$ \\
\hline 7.6 & \multirow[t]{5}{*}{$\mathrm{GVL} \rightarrow 4 \mathrm{PA}$} & $4.53 \times 10^{81}$ & -19.9 & 101470 & \multirow[t]{5}{*}{$4 \mathrm{PA} \rightarrow \mathrm{GVL}$} & $2.24 \times 10^{77}$ & -19.5 & 88823 \\
\hline 76 & & $7.09 \times 10^{68}$ & -16.0 & 96093 & & $3.43 \times 10^{64}$ & -15.6 & 83434 \\
\hline 7600 & & $2.27 \times 10^{32}$ & -5.3 & 75996 & & $1.49 \times 10^{28}$ & -4.9 & 63427 \\
\hline 76000 & & $2.99 \times 10^{18}$ & -1.3 & 67715 & & $1.99 \times 10^{14}$ & -0.9 & 55150 \\
\hline$\infty$ & & $1.62 \times 10^{9}$ & 1.4 & 62040 & & $1.07 \times 10^{5}$ & 1.8 & 49474 \\
\hline 760 & \multirow{4}{*}{$\mathrm{GVL} \rightarrow \gamma-\mathrm{GBL}+\mathrm{CH}_{3}$} & $6.35 \times 10^{74}$ & -17.0 & 120920 & \multirow{4}{*}{$4 \mathrm{PA} \rightarrow$ allyl $+\mathrm{CH}_{2} \mathrm{COOH}$} & $2.13 \times 10^{58}$ & -12.4 & 98005 \\
\hline 7600 & & $4.00 \times 10^{54}$ & -11.1 & 110190 & & $7.31 \times 10^{38}$ & -6.7 & 87198 \\
\hline 76000 & & $2.94 \times 10^{37}$ & -6.1 & 100300 & & $2.54 \times 10^{24}$ & -2.5 & 78687 \\
\hline$\infty$ & & $2.66 \times 10^{24}$ & -2.3 & 92431 & & $3.57 \times 10^{17}$ & -0.6 & 74727 \\
\hline 7.6 & \multirow[t]{2}{*}{$\mathrm{GVL} \rightarrow$ allyl $+\mathrm{CH}_{2} \mathrm{COOH}$} & $1.28 \times 10^{115}$ & -28.7 & 143280 & \multirow[t]{2}{*}{$4 \mathrm{PA} \rightarrow 1-\mathrm{C}_{4} \mathrm{H}_{8}+\mathrm{CO}_{2}$} & $3.99 \times 10^{84}$ & -20.9 & 109670 \\
\hline 76 & & $3.35 \times 10^{108}$ & -26.4 & 146200 & & $3.13 \times 10^{77}$ & -18.5 & 109940 \\
\hline 7.6 & \multirow[t]{6}{*}{$\mathrm{GVL} \rightarrow \mathrm{C}_{3} \mathrm{H}_{6}+\mathrm{cy}\left(\mathrm{OCH}_{2} \mathrm{C}\right)=\mathrm{O}$} & $6.33 \times 10^{92}$ & -22.9 & 120540 & \multirow[t]{12}{*}{$4 \mathrm{PA} \rightarrow 3 \mathrm{PA}$} & $1.51 \times 10^{82}$ & -20.9 & 104290 \\
\hline 76 & & $1.82 \times 10^{90}$ & -21.8 & 124190 & & $1.30 \times 10^{88}$ & -21.9 & 115060 \\
\hline 760 & & $3.89 \times 10^{64}$ & -14.2 & 109760 & & $4.07 \times 10^{70}$ & -16.4 & 109110 \\
\hline 7600 & & $1.16 \times 10^{44}$ & -8.2 & 98538 & & $5.77 \times 10^{43}$ & -8.5 & 94870 \\
\hline 76000 & & $2.33 \times 10^{27}$ & -3.4 & 88805 & & $3.59 \times 10^{23}$ & -2.6 & 83135 \\
\hline$\infty$ & & $5.01 \times 10^{14}$ & 0.31 & 81138 & & $1.49 \times 10^{12}$ & 0.7 & 76261 \\
\hline 7.6 & \multirow[t]{6}{*}{$\mathrm{GVL} \rightarrow \mathrm{CO}+\mathrm{C}_{2} \mathrm{H}_{4}+\mathrm{CH}_{3} \mathrm{CHO}$} & $2.84 \times 10^{95}$ & -23.5 & 123420 & & & & \\
\hline 76 & & $1.78 \times 10^{93}$ & -22.4 & 127490 & & & & \\
\hline 760 & & $1.39 \times 10^{68}$ & -15.0 & 113740 & & & & \\
\hline 7600 & & $9.93 \times 10^{46}$ & -8.8 & 102340 & & & & \\
\hline 76000 & & $1.77 \times 10^{29}$ & -3.6 & 92061 & & & & \\
\hline$\infty$ & & $1.27 \times 10^{15}$ & 0.4 & 83506 & & & & \\
\hline
\end{tabular}

${ }^{a} k=A T^{n} \exp (-E / R T)$, with units of $\mathrm{s}^{-1}$, cal and mol. 
reaction sequence GVL $\rightarrow 4 \mathrm{PA} \rightarrow$ allyl $+\mathrm{CH}_{2} \mathrm{COOH}$, rather than the well-skipping reaction.

Additionally, the branching of the remaining decomposition channels is markedly enhanced at high pressures. Of the two concerted reactions, which form $\mathrm{C}_{3} \mathrm{H}_{6}+2$-oxiranone and $\mathrm{CO}+$ $\mathrm{C}_{2} \mathrm{H}_{4}+\mathrm{CH}_{3} \mathrm{CHO}$, respectively, the latter reaction is more favored than the former one because of the larger entropic effect.

The situation in the case of 4PA is quite different from that of GVL. From Fig. 7(d-f), the pressure has only a minor influence on the branching of the three major consumption channels. The branching of isomerization to GVL drops rapidly with temperature, while the branching of allyl $+\mathrm{CH}_{2} \mathrm{COOH}$ increases correspondingly. It has been mentioned earlier in Section 3.1 that the transition states of TS6, TS7 and TS8, which characterize the remaining consumption channels of 4PA, have lower energies than the CBS-QB3 energies by De Bruycker et al. ${ }^{11}$ so it can be deduced that the contribution from these channels will be even smaller when using the CBS-QB3 parameters for kinetic evaluations.

In all, the upper panels in Fig. 7 demonstrates that the distribution of primary decomposition products is quite sensitive to the pressure, which will certainly affect the subsequent radical chemistry. The upper and lower panels combine to highlight the most important route in initial decomposition of $\mathrm{GVL}$, that is, isomerization to $4 \mathrm{PA}$ followed by $\mathrm{C}-\mathrm{C}$ bond fission into allyl $+\mathrm{CH}_{2} \mathrm{COOH}$. However, although the $\mathrm{C}-\mathrm{C}$ scission of $4 \mathrm{PA}$ and decomposition of $\mathrm{CH}_{2} \mathrm{COOH}$ are rather fast at higher temperatures, the radical chemistry of $4 \mathrm{PA}$, such as $\mathrm{H} / \mathrm{CH}_{3}$ addition, is also expected to be very competitive. In view of this fact, kinetic modeling should be a good way to examine the importance of the falloff regime of decomposition rates.

The calculated rate constants were fitted in the modified Arrhenius expressions, with the $(A, n, E)$ parameters tabulated in Table 2 .

\section{Conclusions}

Detailed reaction kinetics of the initial decomposition of gamma-valerolactone (GVL) has been explored by combining quantum chemical calculations and RRKM/master equation analysis. The branching ratios of primary decomposition products has been determined at a variety of pressures. It has been found that GVL decomposes predominantly via isomerization to 4-pentenoic acid (4PA), except at high temperatures and elevated pressures where the channel to form $\mathrm{CO}$ plus ethene plus acetaldehyde has the largest branching. The channel to the formation of propene plus 2-oxiranone also has a nonnegligible contribution at high temperatures and moderate to high pressures. Interestingly, the formally direct formation of allyl plus $\mathrm{CH}_{2} \mathrm{COOH}$ from GVL has a considerable contribution at very low pressures, but shows a declining reactivity with the increasing pressure.

4PA is an important intermediate in GVL decomposition. Subsequent consumption of this species occurs mainly through the direct cleavage of the allyl-carboxymethyl bond, except at low temperatures under which conversion back to the initial reactant is more likely to occur. In contrary to GVL, the branching of 4PA consumption is insensitive to the pressure. The present study has confirmed that the products of allyl and $\mathrm{CH}_{2} \mathrm{COOH}$, which are crucial for the formation of initial radical pool, primarily come from the reaction sequence GVL $\rightarrow 4 \mathrm{PA}$ $\rightarrow$ allyl $+\mathrm{CH}_{2} \mathrm{COOH}$. The well-skipping reaction only account for a small portion of their concentration.

\section{Conflicts of interest}

There are no conflicts of interest to declare.

\section{Acknowledgements}

This work was supported by the Natural Science Foundation of China (Grants No. 51606122, 91541201). The authors are grateful to the technical support from the Center for High Performance Computing at Shanghai Jiao Tong University.

\section{References}

1 I. T. Horvath, H. Mehdi, V. Fabos, L. Boda and L. T. Mika, Green Chem., 2008, 10, 238-242.

2 D. M. Alonso, S. G. Wettstein and J. A. Dumesic, Green Chem., 2013, 15, 584-595.

3 M. Yang, Z. W. Wang, T. Z. Lei, L. Lin, X. F. He, T. Qi, X. F. Xin, Z. J. Li and J. Shi, J. Biobased Mater. Bioenergy, 2017, 11, 66-72.

4 A. Bereczky, K. Lukacs, M. Farkas and S. Dobe, Nat. Resour., 2014, 05, 177-191.

5 R. Yoshida, D. L. Sun, Y. Yamada, S. Sato and G. J. Hutchings, Catal. Commun., 2017, 97, 79-82.

6 S. H. Zhu, Y. F. Xue, J. Guo, Y. L. Cen, J. G. Wang and W. B. Fan, ACS Catal., 2016, 6, 2035-2042.

7 K. Yan, Y. Y. Yang, J. J. Chai and Y. Lu, Appl. Catal., B, 2015, 179, 292-304.

8 X. Tang, X. H. Zeng, Z. Li, L. Hu, Y. Sun, S. J. Liu, T. Z. Lei and L. Lin, Renewable Sustainable Energy Rev., 2014, 40, 608-620.

9 Z. Xue, F. Liu, J. Jiang, J. Wang and T. Mu, Green Chem., 2017, 19, 5041-5045.

10 Z. Xue, J. Jiang, G. Li, W. Zhao, J. Wang and T. Mu, Catal. Sci. Technol., 2016, 6, 5374-5379.

11 R. De Bruycker, H. H. Carstensen, M. F. Reyniers, G. B. Marin, J. M. Simmie and K. M. Van Geem, Combust. Flame, 2016, 164, 183-200.

12 R. De Bruycker, H. H. Carstensen, J. M. Simmie, K. M. Van Geem and G. B. Marin, Proc. Combust. Inst., 2015, 35, 515523.

13 A. Sudholt, R. Tripathi, D. Mayer, P. A. Glaude, F. BattinLeclerc and H. Pitsch, Proc. Combust. Inst., 2017, 36, 577-585.

14 T. B. Adler, G. Knizia and H.-J. Werner, J. Chem. Phys., 2007, 127, 221106.

15 G. Knizia, T. B. Adler and H.-J. Werner, J. Chem. Phys., 2009, 130, 054104.

16 S. Grimme, S. Ehrlich and L. Goerigk, J. Comp. Chem., 2011, 32, 1456-1465. 
17 L. Goerigk and S. Grimme, J. Chem. Theory Comput., 2011, 7, 291-309.

18 K. Fukui, Acc. Chem. Res., 1981, 14, 363-368.

19 M. J. Frisch, G. W. Trucks, H. B. Schlegel, G. E. Scuseria, M. A. Robb, J. R. Cheeseman, G. Scalmani, V. Barone, B. Mennucci, G. A. Petersson, H. Nakatsuji, M. Caricato, X. Li, H. P. Hratchian, A. F. Izmaylov, J. Bloino, G. Zheng, J. L. Sonnenberg, M. Hada, M. Ehara, K. Toyota, R. Fukuda, J. Hasegawa, M. Ishida, T. Nakajima, Y. Honda, O. Kitao, H. Nakai, T. Vreven, J. J. A. Montgomery, J. E. Peralta, F. Ogliaro, M. Bearpark, J. J. Heyd, E. Brothers, K. N. Kudin, V. N. Staroverov, T. Keith, R. Kobayashi, J. Normand, K. Raghavachari, A. Rendell, J. C. Burant, S. S. Iyengar, J. Tomasi, M. Cossi, N. Rega, J. M. Millam, M. Klene, J. E. Knox, J. B. Cross, V. Bakken, C. Adamo, J. Jaramillo, R. Gomperts, R. E. Stratmann, O. Yazyev, A. J. Austin, R. Cammi, C. Pomelli, J. W. Ochterski, R. L. Martin, K. Morokuma, V. G. Zakrzewski, G. A. Voth, P. Salvador, J. J. Dannenberg, S. Dapprich, A. D. Daniels, O. Farkas, J. B. Foresman, J. V. Ortiz, J. Cioslowski and D. J. Fox, Gaussian, Inc., Wallingford CT, 2013, vol. Revision D.01.

20 K. A. Peterson, T. B. Adler and H.-J. Werner, J. Chem. Phys., 2008, 128, 084102.
21 H.-J. Werner, P. J. Knowles, G. Knizia, F. R. Manby and M. Schutz, in a package of ab initio programs, http:// www.molpro.net., 2015, vol. version 2015.1.

22 P. Celani and H. J. Werner, J. Chem. Phys., 2000, 112, 55465557.

23 K. R. Shamasundar, G. Knizia and H.-J. Werner, J. Chem. Phys., 2011, 135, 054101.

24 Y. Georgievskii and S. J. Klippenstein, MESS, Argonne National Laboratory, 2016.

25 Y. Georgievskii, J. A. Miller, M. P. Burke and S. J. Klippenstein, J. Phys. Chem. A, 2013, 117, 12146-12154. 26 K. G. Joback, MPhil, Massachusetts Institute of Technology, 1984.

27 H. Hippler, J. Troe and H. J. Wendelken, J. Chem. Phys., 1983, 78, 6709-6717.

28 L. Zhao, M. Xie, L. Ye, Z. Cheng, J. Cai, Y. Li, F. Qi and L. Zhang, Combust. Flame, 2013, 160, 1958-1966.

29 L. Ye, L. Xing, W. Yuan, Y. Li, L. Zhang and F. Qi, Proc. Combust. Inst., 2017, 36, 533-542.

30 C. Eckart, Phys. Rev., 1930, 35, 1303-1309.

31 K. Yasunaga, J. M. Simmie, H. J. Curran, T. Koike, O. Takahashi, Y. Kuraguchi and Y. Hidaka, Combust. Flame, 2011, 158, 1032-1036. 